\title{
Traditional Household and Neighbourhood Group: Survivals of the Genealogical-Territorial Societal Pattern in Eastern Parts of the Netherlands
}

\author{
E. W. HofsteE and G. A. Kooy
}

"It does not matter whether marital relations are permanent or temporary; whether there is polygyny or polyandry or sexual license; whether conditions are complicated by the addition of members not included in our own family cycle: the one fact stands out beyond all others that everywhere the husband, wife, and immature children constitute a unit apart from the remainder of the community." This is the conclusion of $\mathrm{R}$. H. Lowie, the well-known and outstanding American cultural anthropologist. So the group consisting of husband, wife, and immature (unmarried) children-with a living Dutch term called "gezin" and with an Anglosaxon artificial term called "nuclear family"-is, according to Lowie, a social unity in every society. This unity, however, has often been integrated in a larger familial group sometimes with such a functional importance that the "gezin" is totally over-shadowed by it. In the non-Western world, we generally find not only such an integration, but also such an over-shadowing. A "gezin" autonomy hardly exists there. The "gezin" has to respect and to obey the norms and decisions of the larger kin group and it also has to comply with the rules of the local community. (It hardly needs mentioning that the larger kin group and the local community in many cases are wholly or for the greater part identical.) This societal type, in which the individual is more a member of its extended family 
and the neighbourhood than of its "gezin", can be defined as a type with a genealogical-territorial pattern.

Where the spirit of individualism and the social-economic process of differentiation go together, this pattern grows weaker and gives way at last to interpersonal relations which for a considerable part are based on individual, revocable choice. If one only has a superficial idea of Western history and of the acculturation in those regions, where whites and non-whites meet each other, one knows that this is true. As to the Western world, here we find in the early Middle Ages - at least in the country-the genealogical-territorial pattern. Today the individual family typically determines its destination itself. The group consisting of husband, wife, and unmarried children liberated itself from the formerly extended family and neighbourhood. Ideological, social, and economic factors caused the loss of the most important functions of these larger units and at the same time a decrease of their power over the smallest kin group, which -becoming a more autonomous unity in a society, characterized by increasing individuation-acquired a unique meaning. Modern Western "gezin" life does not deviate from that of previous generations, only because the "gezin" underwent a very important functional and structural change; it also deviates from it, because the relation between the "gezin" and the other institutions changed fundamentally.

As in other Western countries, the process of "gezin" individualization in Holland did not start at the same time and did not show the same pace everywhere. In general the city led the way and the country followed; the bourgeois class was more progressive in this respect than the nobility and the labourers. The rural regions along the Dutch coast, already taken up in the world economy for many centuries and relatively prosperous, showed clear indications of "gezin" individualization in the middle of the nineteenth century; in the rural regions along the German boundary, long isolated and poor, one can still discover vestiges of the genealogical-territorial pattern. As such may be considered the traditional household and the neighbourhood group. 
We define the traditional household as that type of household which embraces more related individuals than a "gezin" household and this not by incidental individual circumstances, but as a result of an old locally or regionally rooted cultural view. A "gezin" household can embrace only three categories of related persons (father, mother, and children), a traditional household can include many more categories. In a traditional household may live together a "gezin" and the parents of the husband, but also a "gezin" and the widowed mother of the wife, plus the unmarried brother of her mother. The traditional household can contain; (a) several nuclear families, (b) a nuclear family and one or more individuals, who are not members of a "gezin", (c) two, possibly more, nuclear families and one or more individuals, (d) two or more individuals. These four sub-types are all present in those parts of the Netherlands, where the traditional household exists. Are they primarily a consequence of poverty? This question has to be answered in the negative. For in those Western regions, where the agrarian population has the same standard of living as that near the German boundary, the traditional household does not exist any longer as it does in the Eastern regions. It is clear that the continuance of the traditional household finds its most important reason in a familistic spirit, which belongs to a phase of culture in which the process of social differentiation has not yet reached the modern stage and in which the individual does not yet know the same longing to follow his own ways as contemporary urbanized man.

The neighbourhood group is a group arising from and conforming to rules in the minds of the members of a local or regional society. As contrasted with many other neighbourhood groups this neighbourhood group has its sharp limit; one belongs to it or one does not. One joins it according to a certain rule and one likewise leaves it. The rights and duties of the neighbour are fixed and everyone knows them. One can possess a special status in the neighbourhood group, which gives rights and duties not shared by the other group-members. In short, this neighbourhood group is not at all an amorphous group with a vague limit, 
but on the contrary a social unit with a specific structure, specific functions, and a clear outline. Beyond the special rights which the individual can derive from his membership of the neighbourhood group (help during child-birth, wedding, death, harvest, etc.), he also gains a place in local society through this membership. If the newcomer does not take the step necessary to become the neighbour of a number of surrounding people, he will stay an outsider. He cannot be "one of us" if he fails to ask for the neighbour-bond. From the social point of view he stands isolated from those who are geographically his neighbours and this implies that he is a stranger in the community. Therefore it is not surprising that hardly any newcomer dares to settle down in the agrarian community, where the neighbourhood group still exists, without asking for neighbourhood according to the rules in force.

It was not before August 1955 that we were really confronted with the two phenomena which form the subject of this paper. During a study among the agrarian population of the municipality of Winterswijk, situated near the German border, we also had the opportunity to consider the traditional household and the neighbourhood group. The situation at Winterswijk is perhaps not representative in all respects of the part of the Netherlands where these phenomena stemming from an earlier phase of culture are still perceptible. On the other hand it is probable that the problems for the individual, caused by the collision of old norms and new individualism, are the same at Winterswijk as in other places where the genealogical-territorial pattern still exists as an influential "survival". Therefore we can take Winterswijk as an example.

Winterswijk has about 21,000 inhabitants, of whom 10,000 are living in the 9 predominantly agrarian hamlets, situated in a circle around the town (which everyone calls "the village"). In the town agriculture has not yet disappeared; even along the main street one can find farm houses. But the important source of livelihood is the textile-industry. The largest of the 7 textile mills has a labour force of 1000. The agrarian population is 
predominantly Protestant. Only in the hamlet of Meddo near the Roman Catholic municipality of Grol we find a strong minority of Catholics. Type and size of the farms in Winterswijk are rather representative for agriculture on the Dutch sandy soils. The small family farm prevails, and the farm is a so-called mixed farm on which the products of agriculture are used for animal husbandry. There are 1514 farms of which 589 are smaller than 5 ha., of which 638 are larger than 5 but smaller than 10 ha., of which 187 lie between 10 and 15 ha., and of which 100 are over 15 ha.

It was possible to obtain data about the structure of the household on 497 farms at Winterswijk. Thiese 497 farms may be considered as representative for all agrarian enterprises larger than 2 ha. It appeared that a "gezin" household occurs in 252 cases, so this type of household is somewhat more represented in the total sample than the traditional household. It is not so, that, if one comes nearer to the "village", one finds fewer traditional households. Nor do we find a decrease of traditional households in connection with an increase in farm size. If we join together all farms, smaller than $15 \mathrm{ha}$., and we compare them with those over 15 ha., the percentage of traditional households in the first group is 46.5 and in the second one 53.5. From the data obtained at Winterswijk, one cannot state that increasing farm size (and so probably increasing material prosperity) causes decrease of traditional households. The data suggest a connection between traditional household and religious denomination, but the members of the Dutch Reformed Church form such a majority, that it is dangerous to suppose a stronger inclination among the Dutch Reformed to accept the old type of household than among other groups. Moreover the Dutch Reformed Church is a dwelling with many compartments.

An exact knowledge of the structure of the traditional household is important, because every structure causes its own psychological difficulties. It appeared then, that in 125 cases a married couple lives together with the parents-in-law and that in 100 cases a couple lives together with the father or mother of one of 
the partners. It rather seldom happens, that a "gezin" lives together with an individual of the husband's and wife's generation. A "gezin" and an "uncle" (wife's or husband's brother) were found together 14 times, a "gezin" and an "aunt" only 6 times. Probably the relatively high frequency of the threegeneration household must be explained by the old rule of primogeniture. Although modern Dutch law gives every child a similar portion of the legacy, the old idea of primogeniture is not dead at Winterswijk. If possible, the eldest son inherits the farm and the other children, compensated by money, leave it. But the successor accepts the duty "to bring his parents to their end".

The type of traditional household, so frequently found at Winterswijk, has the following consequences:

(a) the child is educated by its parents, its grandparents, and possibly by their still unmarried children (the child's uncles and aunts),

(b) if the younger pair lives together with the parents of the husband, the young woman has to adapt herself to the mother of her husband, who is, in her opinion, the master of the house,

(c) if the younger pair lives together with the parents of the wife, the young man has to adapt himself to his wife's father, who will claim to be the "farmer" until his last gasp of breath,

(d) the partner who lives with his or her parents, is in danger of remaining in the position of a "child" until his old age.

It is impossible here to consider these consequences more thoroughly but it is clear that there is an interesting psychological and sociological problem in the structure of the traditional household. It depends on the sort of structure which problems will arise. If the household consists of a "gezin" and a brother or sister of one of the partners, one may mainly expect difficulties between brother and sister-in-law, whereby the unmarried one of these two is in the weakest position.

Nearly every agrarian family at Winterswijk has accepted the 
neighbour bond, from which it derives rights on the one hand, but from which arise duties on the other hand. Rights form an agreeable side of human existence, but man is inclined to underestimate them. The duties, which man has, are not seldom experienced by him as a heavy restraint. When a child is born in one of the neighbouring families, it may be experienced as very pleasant to visit mother and child with 10 or 11 other near-by women; but when one has a baby herself and she is obliged to see 11 or 12 ladies, the situation has a fundamentally other character. When one of the members of a person's family dies and his neighbours pay (in accordance with their neighbour duty) the death announcements, then this is hardly noticed by him, for it is a matter of course; but when someone dies in a neighbouring family and he is obliged to pay the death announcements, then this is not always a task which he fulfils with all his heart. Especially younger people feel it as a burden, but they do not dare to throw it off, for the norm lies deeply anchored.

The traditional household and the neighbourhood group are acceptable to the individual as long as he considers himself primarily a member of the larger genealogical unit and the local unit. They are acceptable for man in "primitive" society, in societies geographically and socially isolated, little differentiated, and lacking a money-economy. When the "primitivism" of society' is broken through, however, there grow tensions in and between members of this society, which may be hidden from the eyes of outsiders, but which are intensive. Traditional household and neighbourhood groups are today considered by many younger people in the eastern parts of the Netherlands as serious restraints. Modern culture has awakened wishes and desires which do not reconcile with the old norms and forms. There are indications that those old norms and forms give way to entirely other ones, but it seems that many and long-lasting tensions are reserved for the agricultural population in the Eastern parts of the Netherlands, for the power of the old norms is great. 